http://jmscr.igmpublication.org/home/ ISSN (e)-2347-176x ISSN (p) 2455-0450

crossref DOI: https://dx.doi.org/10.18535/jmscr/v9i12.30

Journal Of Medical Science And Clinical Research

\title{
Profile of Bile Duct Injuries Occurring as a Complication of Open/Laparoscopic Cholecystectomy
}

Authors

\author{
Dr V. Manmadha Rao ${ }^{1}$, Dr D. Narendra Babu², Dr T. Durga Samyukta ${ }^{3}$ \\ ${ }^{1}$ M.S, Professor of General Surgery, Andhra Medical College, Visakhapatnam, Andhra Pradesh \\ ${ }^{2}$ M.S., Senior resident, Department of General Surgery, Andhra Medical College, Visakhapatnam, \\ Andhra Pradesh \\ ${ }^{3}$ M.B.B.S, Post Graduate in Department of General Surgery, Andhra Medical College, Visakhapatnam, \\ Andhra Pradesh
}

\begin{abstract}
Background: In utero complex development of the liver, and the biliary system can result in multiple anatomic variations. Knowledge about these anatomic variants is required for the safe performance of any hepatobiliary surgery. Cholecystectomy remains the major source ofbile duct injuries (BDI) given the frequency with which it is performed. Various studies worldwide have documented an increase in the frequency of bile duct injuries associated with the laparoscopic approach, ranging from $0.4 \%$ to $1.3 \%$.

Aims and Objectives: To study the incidence of bile duct injuries managed at our hospital and note the conditions contributing to them, document the site of the injury and their methods of management.

Materials and Methods: A prospective observational study was performed with 25 patients from July 2018 to June 2020 in the Department of General Surgery, King George Hospital, Visakhapatnam. Patients of age 35 to 70 years who had BDI as a complication of open/laparoscopic cholecystectomy were included.

Details regarding the presence of aberrant anatomy, timing of the onset of symptoms and the time from injury to recognition of BDI were noted.

Results: The incidence of bile duct injury was $1.82 \%$ with a mean age of 48.7 years. Majority of the injuries were seen in patients undergoing cholecystectomy for cholecystitis $>72$ hours duration. BDI was documented to be of common hepatic duct (CHD) in 40\%, common bile duct (CBD) in 40\%, and cystic duct in $20 \%$.

Conclusion: Factors contributing to BDI are acute cholecystitis, cholangitis, pancreatitis, and choledocholithiasis. Definitive repair should be done only after detailed investigation of site and type of injury.

Keywords: Bile duct injury, laparoscopic cholecystectomy, open cholecystectomy, complications of cholecystectomy, Iatrogenic injury of bile duct, hepatobiliary surgery, common bile duct, cystic duct, anomalies of biliary system.
\end{abstract}

\section{Introduction}

The biliary tract is an organ system that performs the function of collection, storage, and delivery of bile to the Gastrointestinal tract. Diseases of the biliary tract can be extremely painful, debilitating, and occasionally life threatening. In utero 
complex development of the hepatobiliary system can result in multiple anatomic variants. Knowledge of these anatomic variants with careful dissection, and identification of structures is needed for the safe performance of hepatobiliary surgeries. Technical errors or judgement can be dangerous, and can lead to death of the patient. Positive results of hepatobiliary surgery require prompt judgement, technical acumen, and attention to anatomical details.

Cholecystectomy remains the major source of postoperative biliary injuries given the frequency with which it is performed. In 1989, in United States, a review of more than 42,000 open cholecystectomies performed, documented an incidence of $0.2 \%$ of biliary injuries. In the years 1991-1993, a review of nearly 1,25,000 laparoscopic cholecystectomies by Strasberg and colleagues reported an incidence of biliary injuries of $0.85 \%^{2}$

\section{Aims and Objectives}

The objectives of the current study are-

1. To study all cases of bile duct injury managed at our hospital, and note the conditions contributing to them, document the site of the injury and their methods of management.

2. To study the incidence of bile duct injuries.

\section{Review of Literature}

The main aim of the cholecystectomy is to safely separate the gall bladder from its blood supply, the bile duct and the liver. With recent advances, 90\% of the cholecystectomies are performed with laparoscopic approach. But open cholecystectomy remains an extremely safe procedure with low morbidity and mortality. Roslyn and colleagues analysed 42,474 open cholecystectomies and reported $0.17 \%$ mortality and $0.2 \%$ incidence of bile duct injuries ${ }^{1}$. Even with extensive experience with laparoscopic surgery, the incidence of intraoperative injury with open cholecystectomy remains about half that of the laparoscopic cholecystectomy.

It has been argued that the inexperience of the surgeon is the primary culprit in bile duct injuries following cholecystectomy. With an increase in familiarity with the laparoscopic technique, the number of injuries will decrease, the so called "LEARNING CURVE EFFECT"8. Many authors have shown an inverse relationship between the incidence of bile duct injuries and the number of cases performed ${ }^{4,9,10}$. However, reports of significant bile duct injuries inflicted by surgeons with considerable experience continue to $\operatorname{appear}^{14,9}$.

\section{Etiology}

The common reason for most bile duct injuries during cholecystectomy is either a technical error or misinterpretation of the anatomy, such as

1. Misinterpretation of the bile ducts as the cystic duct.

2. Misinterpretation of the common bile duct as the cystic duct.

3. Misinterpretation of an aberrant right sectoral hepatic duct as the cystic duct.

Technical reasons include

1. Failure to occlude the cystic duct securely.

2. Dissecting more into the liver bed rather than the gall bladder fossa superficially.

3. Injudicious use of electrocautery for control of bleeding or dissection.

4. Excessive traction on cystic duct with tenting upwards of common hepatic duct.

5. Injudicious use of clips to control bleeding.

6. Improper techniques of ductal exploration.

The most common variation in anatomy is anomalous insertion of the cystic duct into the common bile duct. 

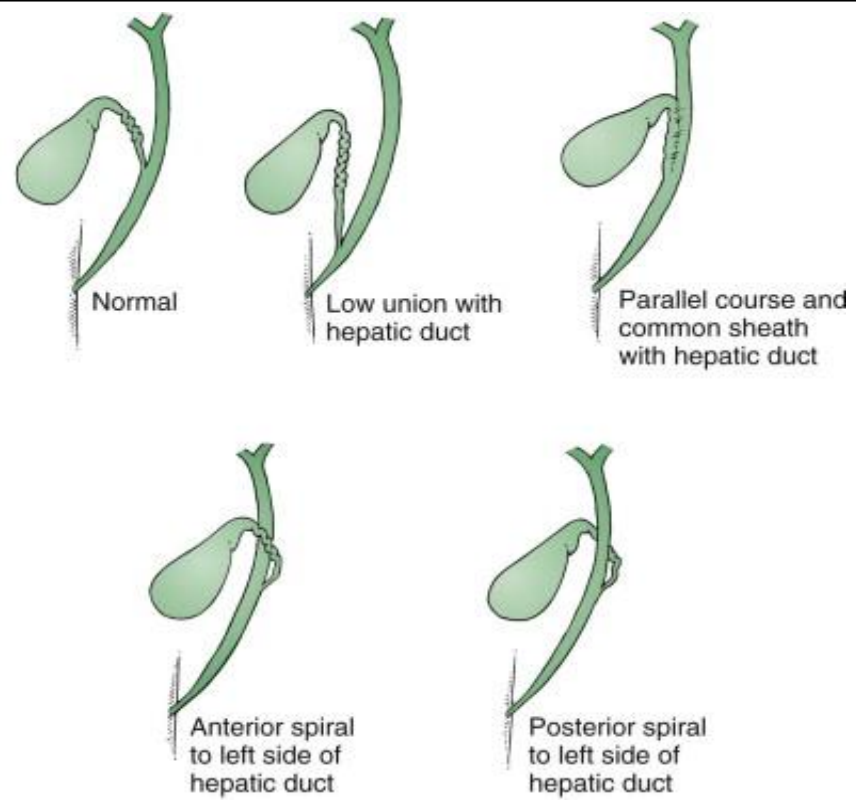

Fig.1 Variations of the cystic duct

The cystic duct joins the hepatic duct at an angle of about 40degrees in $64-75 \%$ of individuals. In $17-23 \%$, the cystic duct parallels the hepatic duct for a longer or shorter distance and may even enter the duodenum separately. This is called the "absence". In 8-13\%, the cystic duct may pass inferior or superior to the common hepatic duct to enter the latter on the left side. In the parallel type of junction, the common bile duct is at risk from the surgeon attempting to ligate the cystic duct.

In some cases, the cystic duct is relatively short, and misinterpretation of the anatomy can occur quickly. The surgeon then may mistake the common bile duct for the cystic duct and ligate it and remove it with the attached gall bladder. This type of injury appears to be much more common after laparoscopic cholecystectomy than open procedure and is well described ${ }^{18}$.

The common hepatic duct (CHD) is formed by the union of the right and left hepatic ducts in the porta at the transverse fissure of the liver. Its lower end is defined as its junction with the cystic duct. The distance between these points varies from $1.0 \mathrm{~cm}$ to $7.5 \mathrm{~cm}$.

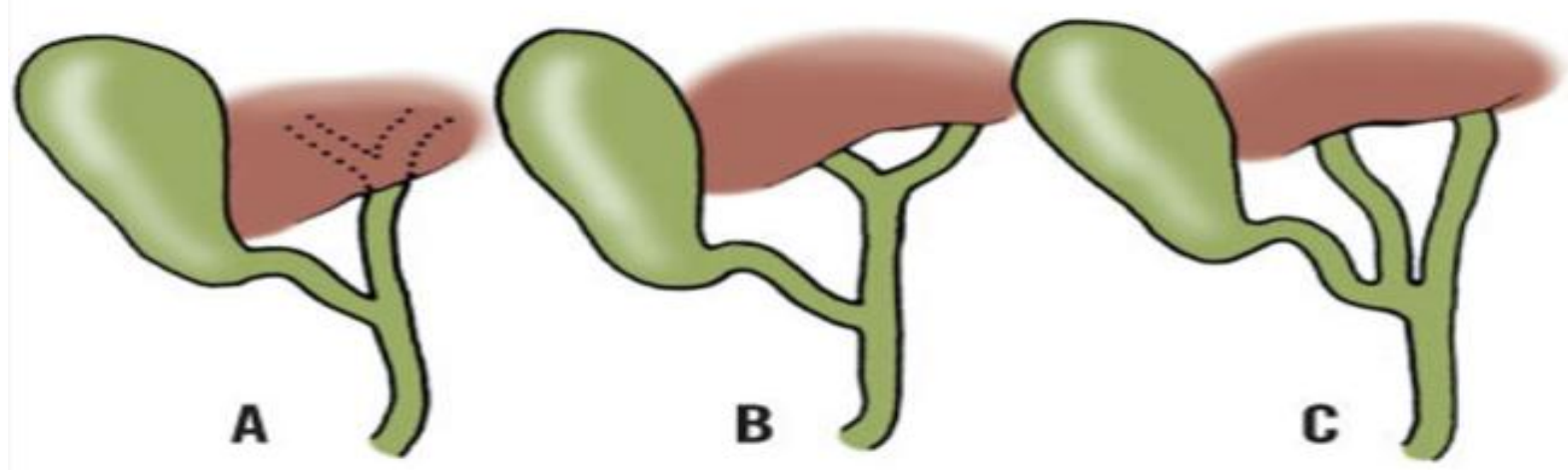

Fig.2 Variations of hepatic ducts. A. union of right and left hepatic ducts in the liver. B, Extrahepatic union of hepatic ducts (Normal). C, Distal union of hepatic ducts resulting in the absence of a common hepatic duct
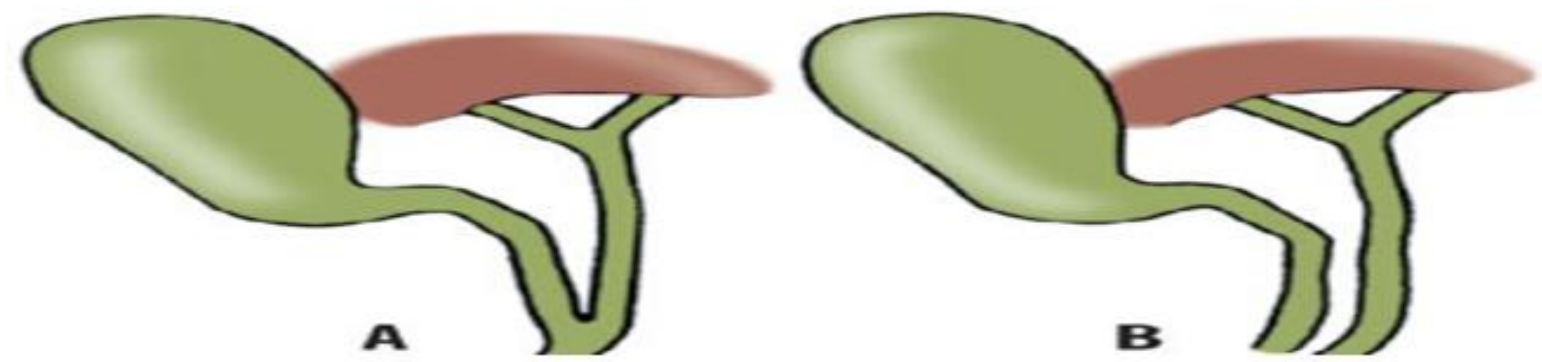

Fig.3 Variations of the common bile duct. A. Low junction of cystic and common hepatic ducts results in the shortened common bile duct. B. Absence of a common bile duct. 


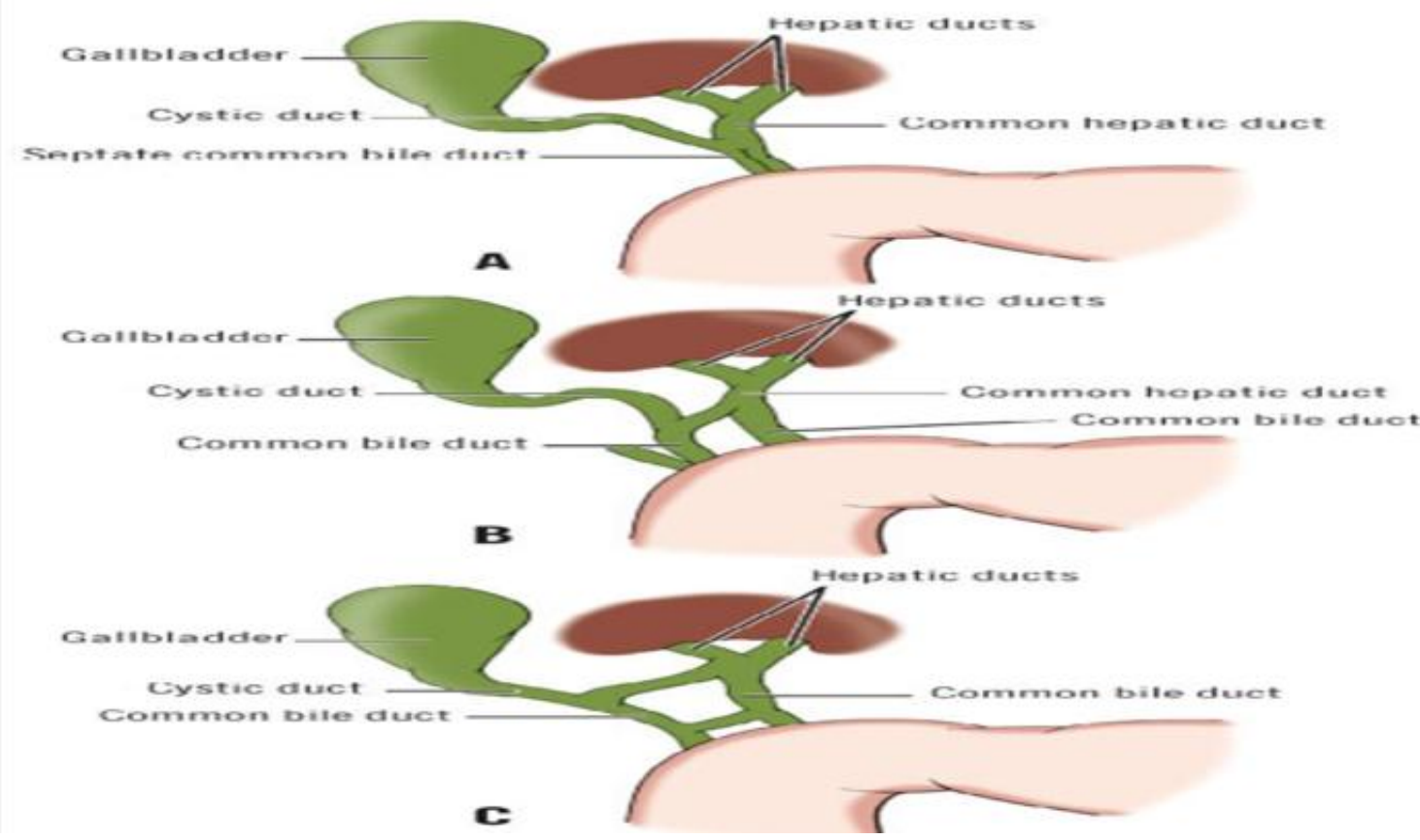

Fig.4 Duplications of the common bile duct. A. Double and parallel lumina of the common bile duct. B. "X" type of anastomosis between duplicated bile ducts. C. "X" and "H" types of anastomosis between duplicated bile ducts.

Aberrant hepatic arteries frequently occur $(46 \%$ according to Van Demme ${ }^{24} ; 45 \%$ according to Suzuki et $\mathrm{al}^{25} ; 43 \%$ according to Healey et $\mathrm{al}^{26}$; $41 \%$ according to Michaels $^{21}$ ). In an exhaustive study of the cystic artery, Michaels ${ }^{21}$ described 12 types of double cystic arteries; less common than duplications is a recurrence of the superficial branch.

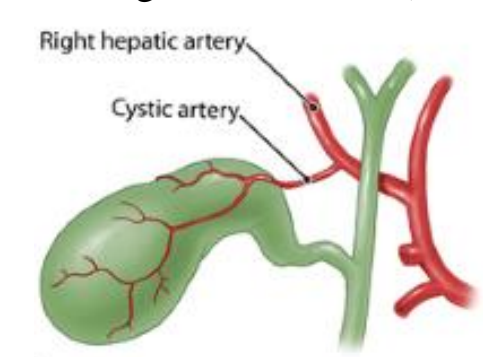

A

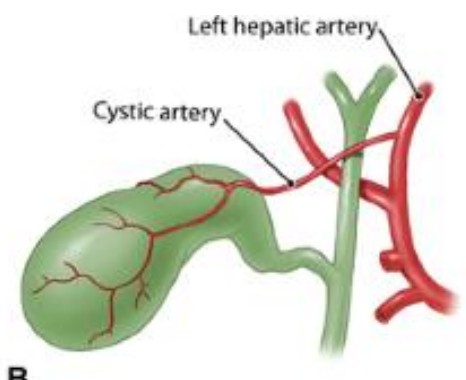

B

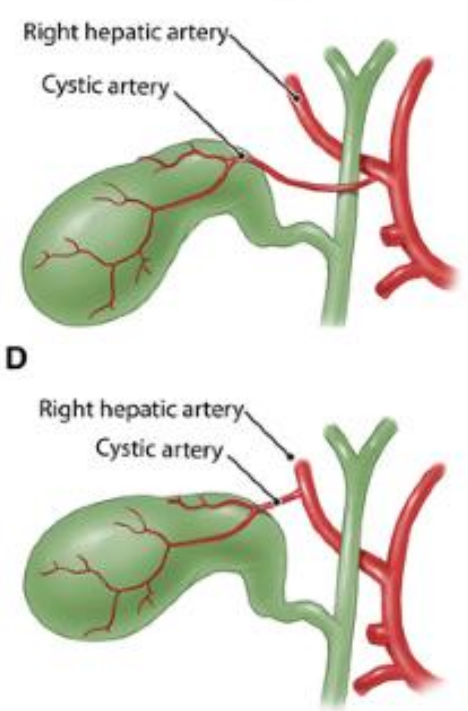

$\mathbf{F}$

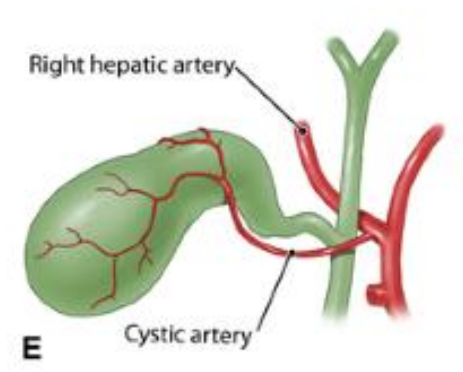

E

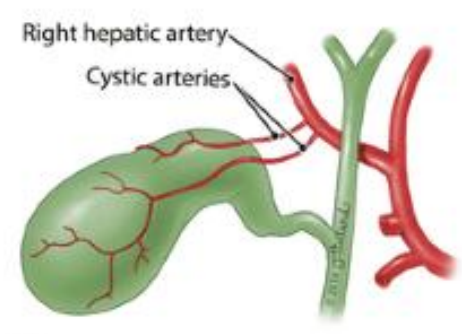

G

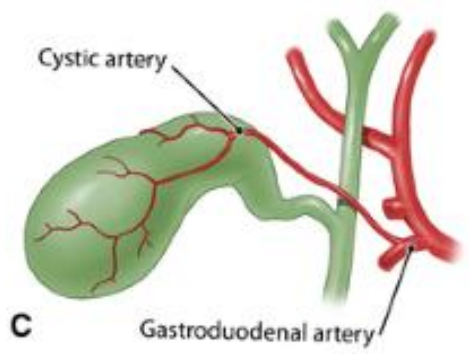

Fig.5 Variations of origin and course of cystic artery 
Late biliary stricture formation, in the absence of overt injury, may result from extensive periductal dissection and consequent interruption of axial blood supply of the duct.

In cases with acute cholecystitis, there can be severe inflammation in the porta hepatis and Calot's triangle, which significantly distorts the anatomy. Fletcher et, $\mathrm{al}^{12}$. reported that complex cases, including acute cholecystitis, cholangitis and gall stone pancreatitis are with increased incidence of bile duct injuries (1.7\%). Factors such as chronic inflammation, obesity, fat in periportal area, inadequate exposure and bleeding that obscure the operative field appear to increase the risk of bile duct injury. The risk of bile duct injury is also higher in patients with complicated gall stone disease than patients with chronic cholecystitis or symptomatic cholelithiasis.

Early reports of laparoscopic bile duct injury showed bleeding and subsequent attempts to achieve haemostasis as major contributing factors to bile duct injury. Blind placement of clips or indiscriminate electrocautery use must be avoided to prevent injury to the right hepatic artery or common hepatic artery; the cystic artery should be divided close to the gall bladder.

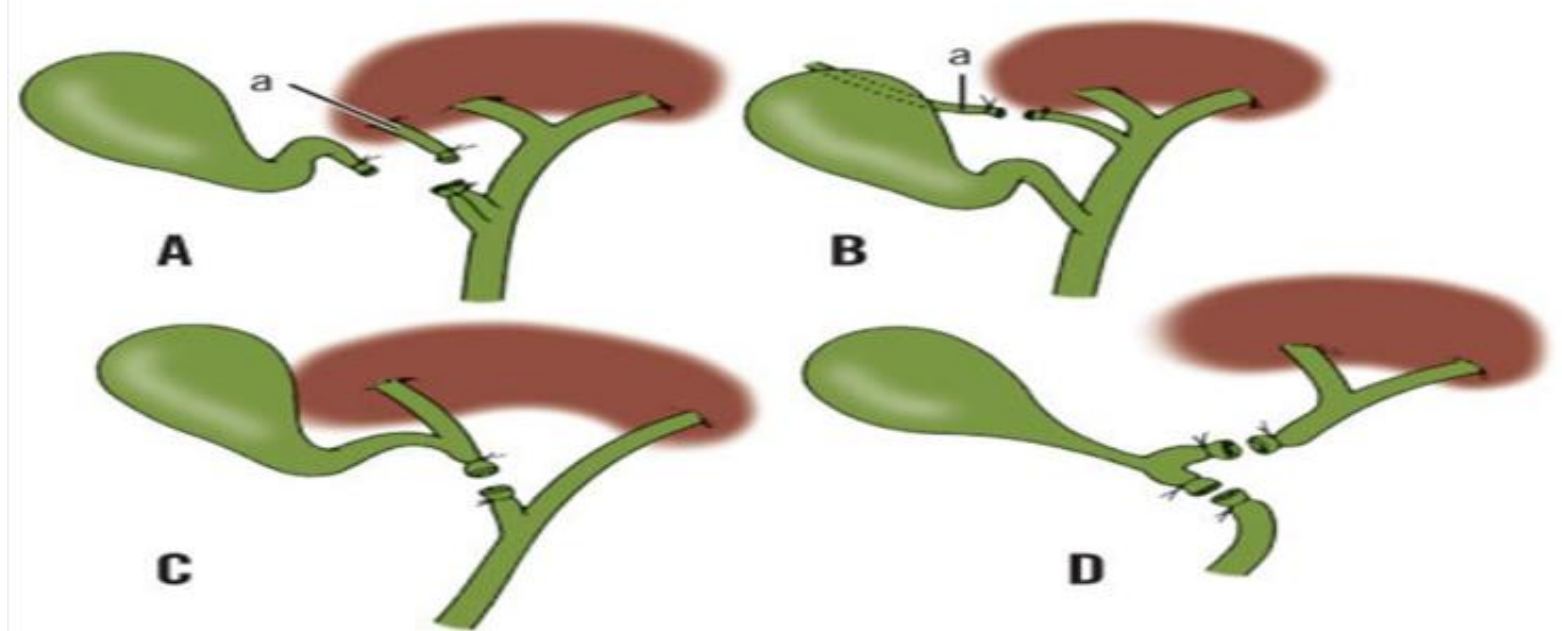

Fig. 6 Possible iatrogenic injuries to the biliary tract. A Ligation of an accessory hepatic duct (a) together with cystic duct. B, Ligation of an accessory hepatic duct (a) instead of the cystic duct. C, Ligation of right hepatic duct below the anomalous entry of cystic duct. D, Short cystic duct under tension may angulate common bile duct. One or both limbs may be inadvertently ligated.

\section{Management}

While ultrasound may provide valuable information regarding the level of biliary injury, a good quality computed tomography (CT) scan will demonstrate a dilated biliary tree and help localise the level of ductal obstruction in patients with strictures. Magnetic resonance cholangiopancreatography (MRCP) has evolved as a potentially valuable tool in evaluating the proximal bile duct injuries. Endoscopic cholangiography also has a role in the diagnosis and treatment of patients with bile leakage from the cystic duct stump or a laceration from the common bile duct.

The most appropriate management of bile duct injuries depends on the type of injury and whether the damage is identified immediately or sometime after the operation. Regardless of the location, initial repair of the damage recognised at the time of surgery should have two basic aims- 1 . Maintenance of length of the duct below the hilum without the sacrifice of tissue, 2. Avoidance of uncontrolled postoperative bile leak. Complete duct transection can be addressed with an end-to- 
end anastomosis over a T-tube or with a Roux-enY Hepaticojejunostomy.

Those type of injuries that are recognised in the immediate postoperative period usually present with bile leak from the wound or with biliary peritonitis. Provided there is no distal obstruction, this kind of injury should result in spontaneous closure.

Bile duct injuries that are identified at an interval after initial surgery present with late bile duct stenosis and strictures. The principles of management of such injuries include 1. Exposure of healthy proximal bile duct draining all areas of liver.

1. Preparation of a suitable segment of distal mucosa for anastomosis.

2. Creation of a mucosa-to-mucosa sutured anastomosis of the bile ducts to the distal conduit (almost always a Roux-en-Y loop of the Jejunum).

\section{Materials and Methods}

The present study was a Prospective observational study conducted with patients aged 35-70 years of age who were admitted to the Department of General Surgery, King George Hospital, Visakhapatnam during a period of 2 years from July 2018 to June 2020. Patients with bile duct injuries as a complication of open/laparoscopic cholecystectomy done in King George Hospital and also those who were referred with bile duct injuries occurring as a complication of cholecystectomy done elsewhere, were included in the study. Bile duct injuries occurring during surgeries (like pancreaticoduodenectomy for malignancy of pancreas) or procedures(like ERCP) and injuries following blunt and penetrating injuries of the abdomen were excluded from the study.

A prospective analysis was done on all patients with an iatrogenic bile duct injuries from July 2018 to June 2020. A retrospective study for bile duct injuries during the period of January 2016 to May 2018 was done using the available hospital records. The case papers, referral letters, operative and postoperative records were scrutinized and data collected.

For the injuries sustained during cholecystectomy, age, gender, presence of aberrant anatomy, presence of gall stone pancreatitis, acute cholecystitis or cholangitis, the timing of recognition of the bile duct injury and timing of onset of symptoms after the procedure were noted. The type of injury and the timing from injury to the definitive management were analysed. Intraoperatively, bile leak either from bile ducts or gall bladder bed is considered as bile duct injury. Postoperatively presence of biliary drainage, failure to recover along expected lines, peritonitis is considered as indicators of bile duct injury.

Major BDI included partial laceration to complete transection of the CHD, CBD, or major segmental ducts at the porta hepatis. Minor leaks from the cystic duct or gall bladder bed were deemed minor BDI.

A sample size of 385 was calculated using nmaster software based on the incidence of complications in people undergoing laparoscopic cholecystectomy as being $0.5 \%$, with a relative precision of $10 \%$ and an alpha error of $5 \%(95 \%$ confidence interval).

\section{Results}

Age Distribution: A total of 25 bile duct injuries were included in this study. The incidence of bile duct injury was $1.82 \%$. with a mean age was 48.7 years with a standard deviation of 14.04 and range of 35 to 70 years. 
Table 1: Distribution of age and sex among the study population

\begin{tabular}{|c|c|c|c|}
\hline Age & Males & Females & Total \\
Range(yrs) & & & 3 \\
\hline $35-40$ & 1 & 2 & 3 \\
\hline $40-45$ & 1 & 3 & 7 \\
\hline $45-50$ & 2 & 5 & 5 \\
\hline $50-55$ & 1 & 4 & 5 \\
\hline $55-60$ & 1 & 0 & 1 \\
\hline $60-65$ & 1 & 0 & 25 \\
\hline $65-70$ & 9 & 16 & 1 \\
\hline Total & & & \\
\hline
\end{tabular}

Laparoscopic vs Open Cholecystectomy: The majority of bile duct injuries were seen in patients undergoing cholecystectomy for cholecystitis of $>72$ hours duration. Among the 25 cases, $80 \%$ were done laparoscopically and of the 20 cases done laparoscopically, 8 were converted to open procedure.

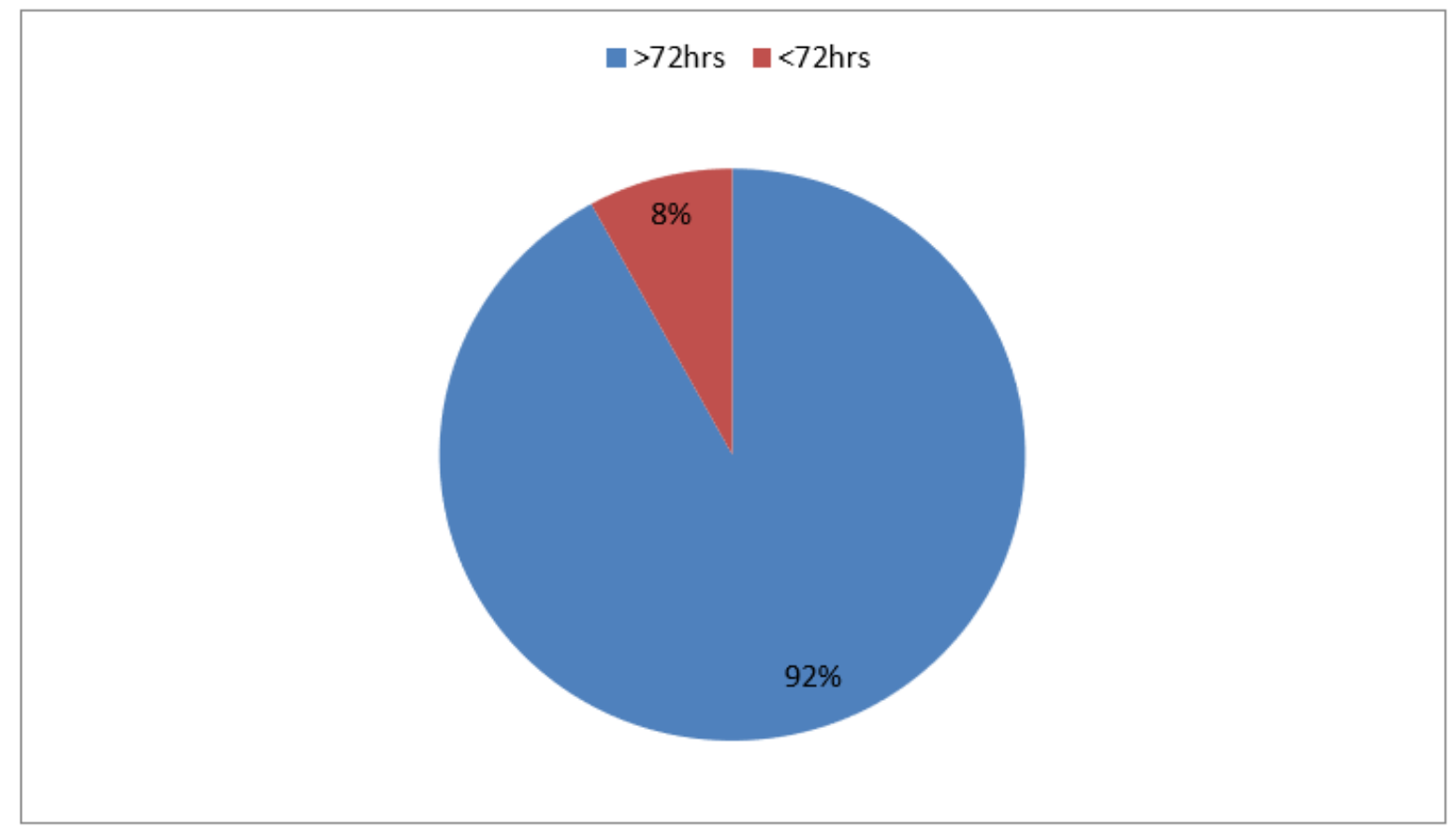

Chart.1 Timing of cholecystectomy from the onset of symptoms 


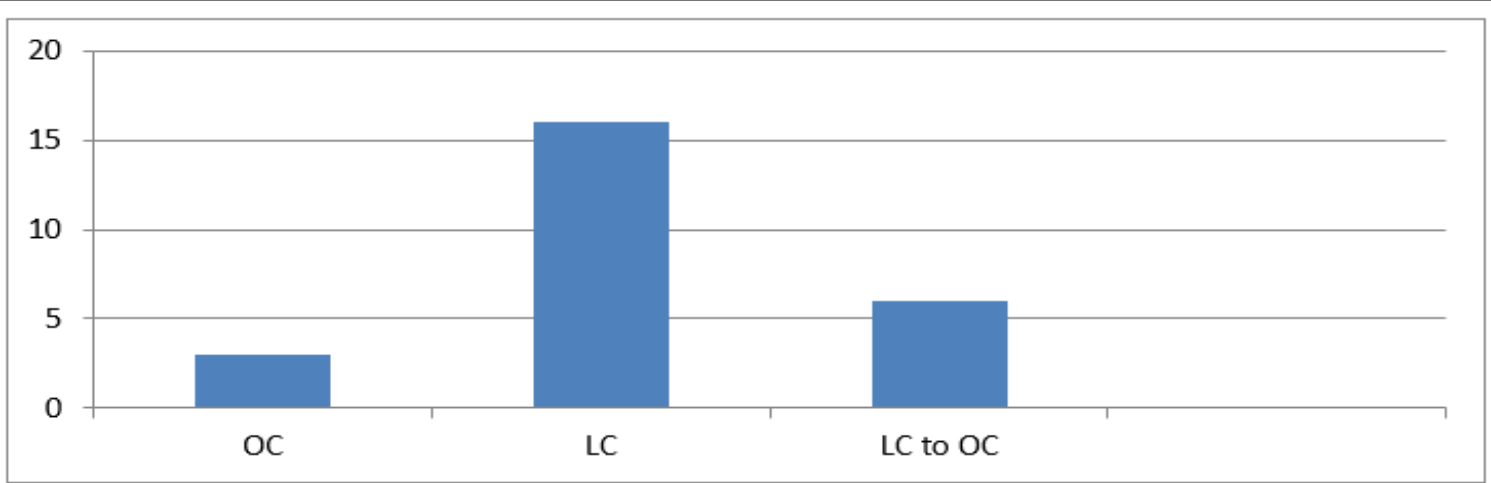

Chart.2 Route of cholecystectomy

Timing of Recognition: Among the 25 cases, 5 were documented BDI referred to our hospital. BDI was recognised intraoperatively in $32 \%$, in the early postoperative period( $<1$ week) in $56 \%$ and in the late postoperative period in only 3 cases.

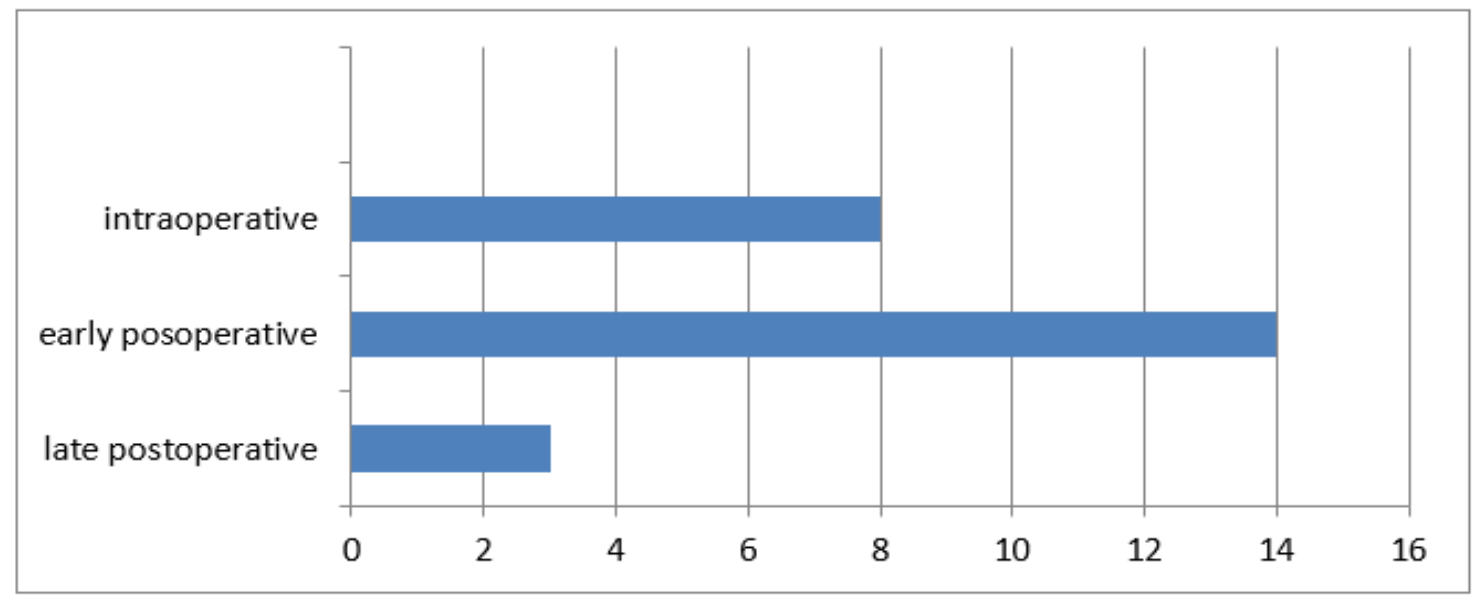

Chart.3 Time to diagnosis of BDI

Risk Factors: $28 \%$ of the bile duct injuries were identified in patients with risk factors like cholangitis (4\%), pancreatitis (4\%), choledocholithiasis (8\%) and cholecystitis $>72$ hours $(12 \%)$.
Site of Injury: BDI was documented to be in CHD in $40 \%$, CBD in $40 \%$ and the cystic duct in $20 \%$.

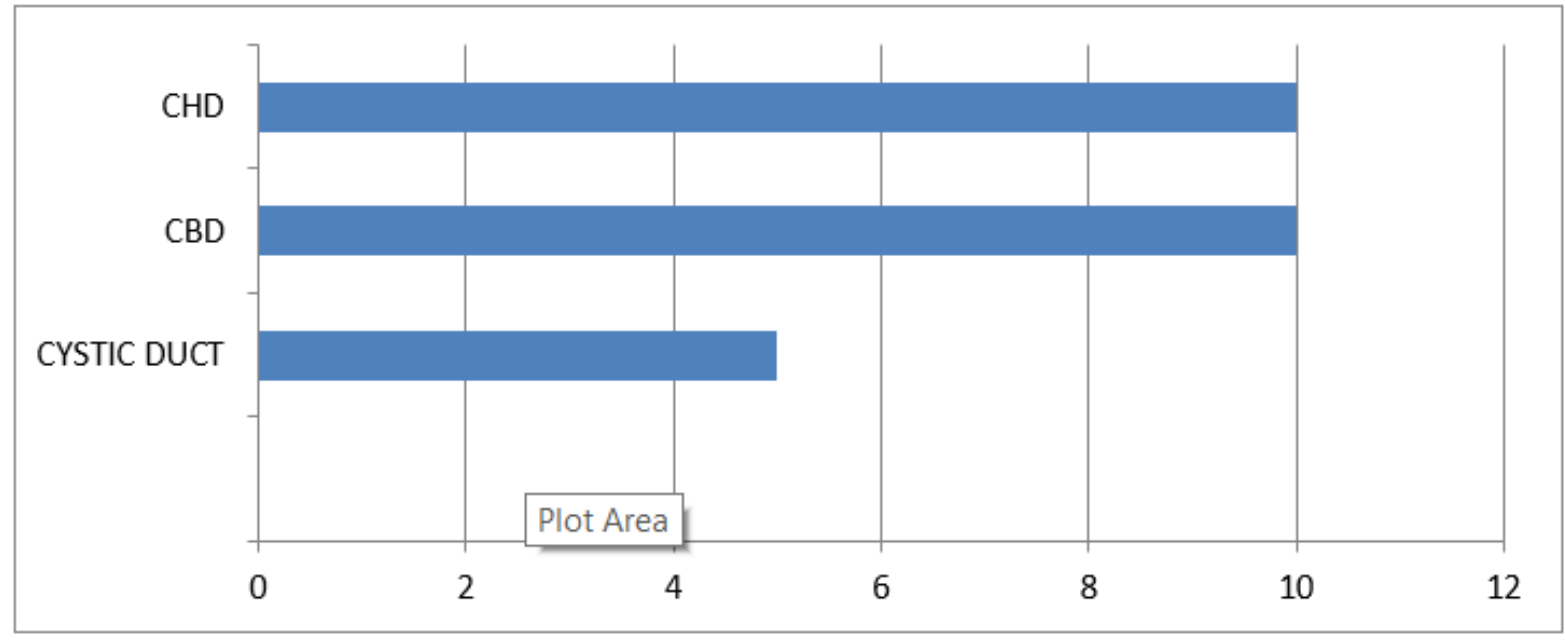

Chart.4 Sites of BDI 
Type of Injury: $36 \%$ of the BDI were Strasberg type A, which was the most common injury identified in our study. $20 \%$ were Strasberg type
E1, 12\% were Strasberg type D, 20\% were Strasberg type E2, and 12\% were Strasberg type E3.

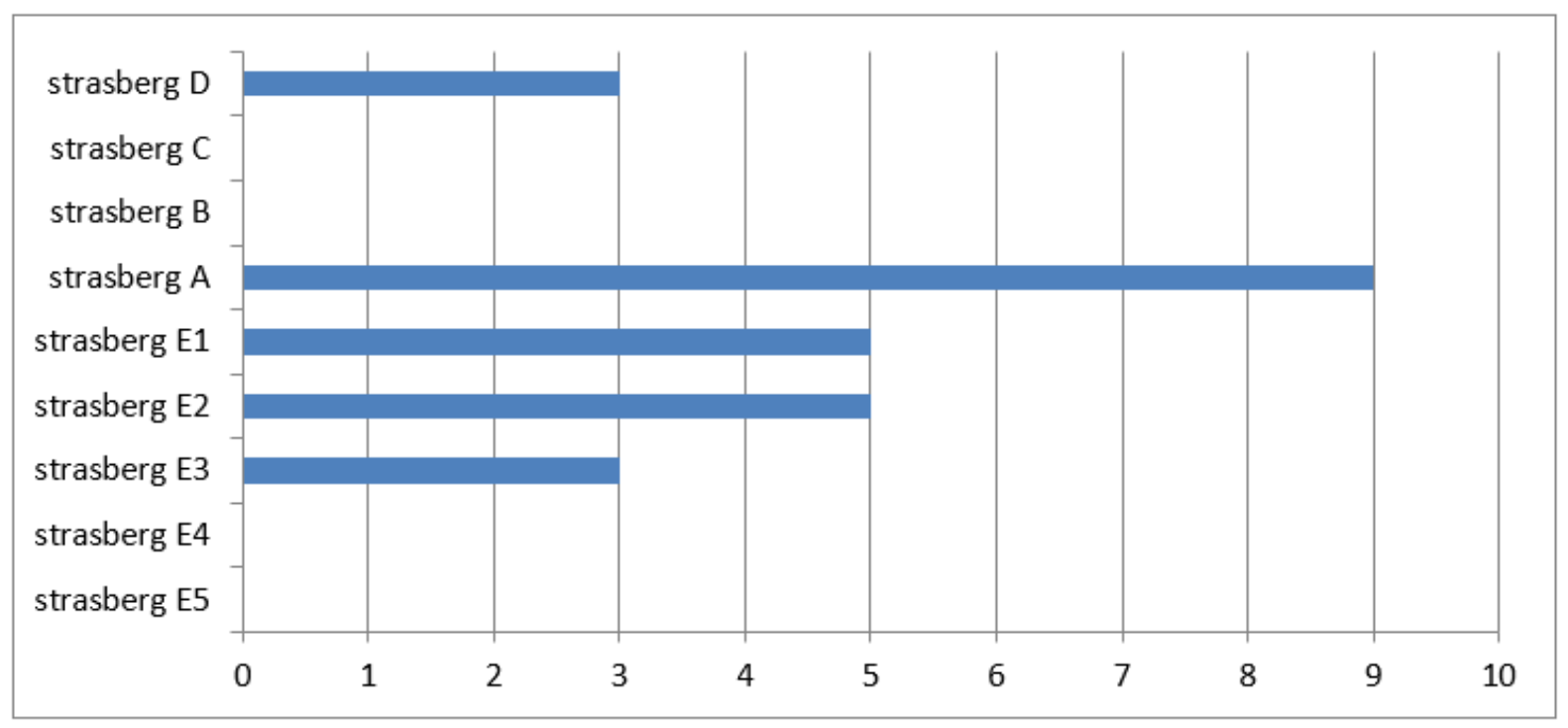

Chart.5 Strasberg classification of BDI noted in the study

Treatment Modalities: Of the 8 cases of BDI identified intraoperatively, 2 were sutured with absorbable materials in interrupted fashion; 3 required clipping of the cystic duct; one required choledochoduodenostomy and $\mathrm{T}$ - tube drainage was done in the remaining 2 cases. 14 cases of BDI were identified in the early postoperative period out of which 7 underwent hepaticojejunostomy. 2 cases required choledochoduodenostomy, 2 were managed with end-to-end anastomosis of the duct with a stent in situ. 2 cases were managed with endoscopic cholangiopancreaticography (ERCP) stenting and 1 with T-tube drainage. 3 cases of BDI were recognised in the late postoperative period and were managed with a hepaticojejunostomy.

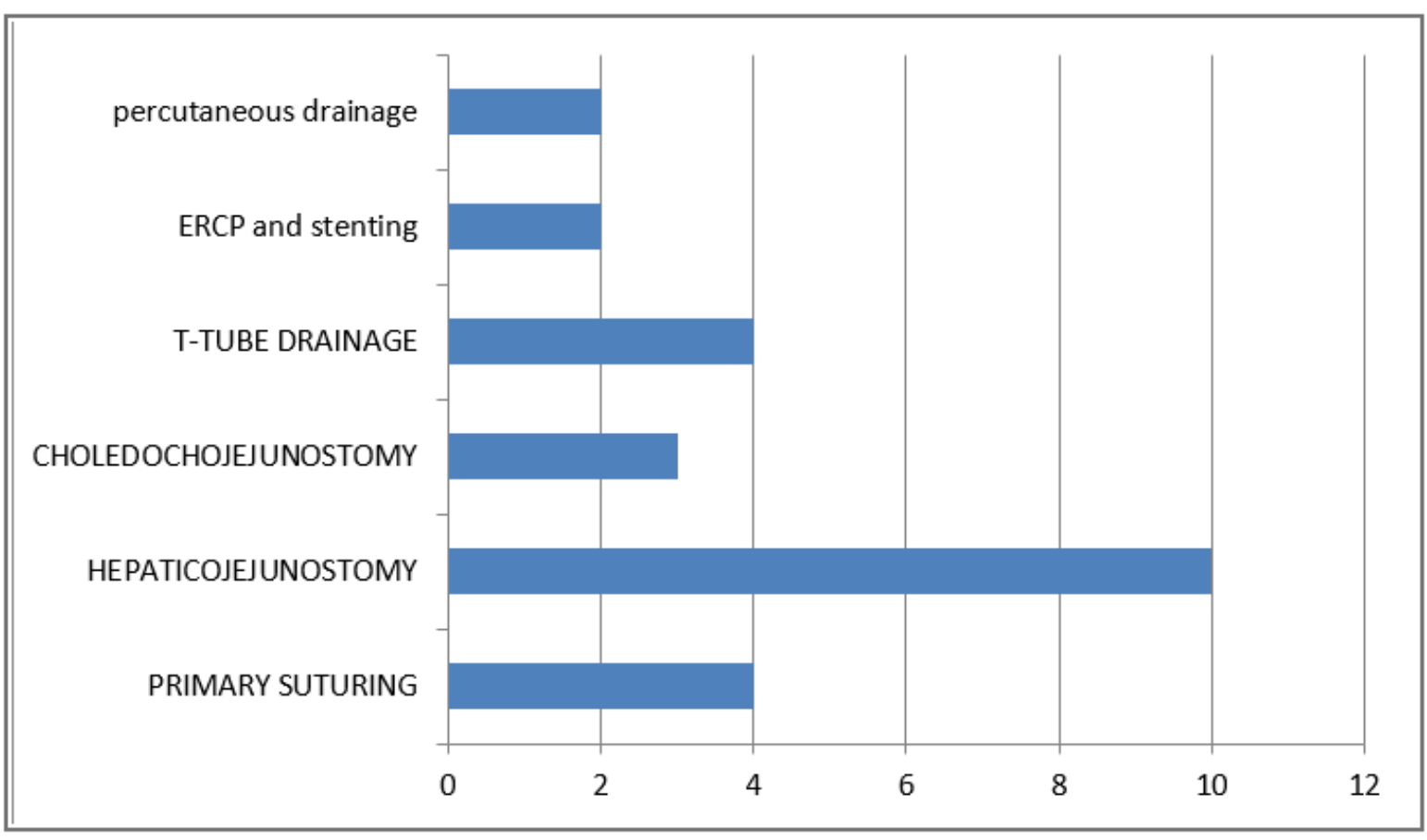

Chart.6 Treatment modalities for BDI in the study 


\section{Discussion}

Diseases of the biliary tract can be excruciating, debilitating, and occasionally life threatening. The complex development of liver and the biliary system in utero can result in multiple anatomic variations. Absolute knowledge about these anatomic variations with careful identification of the structures at the time of surgery is a minimal requirement for the safe performance of any hepatobiliary surgery. Errors in technique or judgement can be disastrous to the patient, resulting in morbidity or mortality. Additionally, the surgeon of today must be able to integrate surgical options with the broadening array of radiologic and endoscopic treatment options in the management of diseases of the biliary system.

Cholecystectomy, whether open or laparoscopic, remains the major source of bile duct injuries given the frequency with which it is performed. Strasberg and associates reported an incidence of $0.3 \%$ of injuries in a literature review of more than 25,000 open cholecystectomies since 1980. Several studies worldwide have documented a marked increase in the incidence of bile duct injuries associated with the laparoscopic approach, ranging from $0.4 \%$ to $1.3 \%$.

Table 2 Similar studies conducted

\begin{tabular}{|c|c|c|c|}
\hline Author & Study centre & Place & Type of study \\
\hline Present study & $\begin{array}{c}\text { King George } \\
\text { Hospital }\end{array}$ & Visakhapatnam & Prospective study \\
\hline Chetan Anand & $\begin{array}{l}\text { M.S.Ramaiah } \\
\text { medical college }\end{array}$ & Bengaluru & Prospective study \\
\hline Lillemoe KD & $\begin{array}{l}\text { John Hopkins } \\
\text { medical institution }\end{array}$ & $\begin{array}{c}\text { United states of } \\
\text { America }\end{array}$ & Prospective study \\
\hline $\begin{array}{l}\text { R.W.Strong, } \\
\text { K.Slater }\end{array}$ & $\begin{array}{c}\text { Princess Alexander } \\
\text { hospital }\end{array}$ & Australia & Retrospective study \\
\hline $\begin{array}{l}\text { Steven D. } \\
\text { Schwaitzber }\end{array}$ & $\begin{array}{l}\text { Harvard medical } \\
\text { school }\end{array}$ & $\begin{array}{c}\text { United states of } \\
\text { America }\end{array}$ & Prospective study \\
\hline Caitlin Halbert & $\begin{array}{l}\text { Stony brook } \\
\text { university }\end{array}$ & $\begin{array}{c}\text { United states of } \\
\text { America }\end{array}$ & $\begin{array}{l}\text { Prospective and } \\
\text { retrospective study }\end{array}$ \\
\hline Bernard W.Renz & $\begin{array}{c}\text { Ludwig-maximillians } \\
\text { university }\end{array}$ & Germany & Prospective study \\
\hline
\end{tabular}

In the present study, the incidence of bile duct injuries was higher in females (64\%) which is similar to the study performed by Anand Chetan in Bengaluru. Female to male ratio in present study was $1.7: 1$ which is similar to $1.27: 1$ in the study done by Anand Chetan. The higher incidence in females is due to higher predilection of females for gall stone disease.
The majority of patients in the present study were of age between 45-60 years, which is similar to 40-60 years inthe study conducted by Anand Chetan.

Risk of bile duct injuries during cholecystectomy is more in acute phase $<72$ hours after the onset of symptoms. Among 25 patients with bile duct injuries, $92 \%$ of the cases were done after 72 hours of onset of symptoms. Despite expectations 
that the rate of BDI would decrease over time as the "Learning Curve" of laparoscopic cholecystectomy flattened, the rates appear to have reached a plateau, as evidenced by a recent review of nearly 1.6 million cholecystectomies performed by Medicare beneficiaries. These studies revealed a steady $0.5 \%$ incidence of BDI from 1992 to 1999. The failure in laparoscopic cholecystectomy leading to bile duct injuries can be attributed to anatomic variations, factors inherent to laparoscopic technique like lack of depth perception and inadequate training.

The rate of bile duct injuries in our study was slightly higher being $1.82 \%$ when compared to other studies where the rate of bile duct injuries following laparoscopic cholecystectomy was noted between 0.4 to $0.6 \%$. This could be due to the learning curve for the laparoscopic surgery in our institution.

$8 \%$ of the bile duct injuries were noted in patients undergoing cholecystectomy for cholecystitis $<72$ hours, compared to $12 \%$ by similar study by Anand Chetan. Bile duct injuries identified intraoperatively was $32 \%$ whereas it was higher in study conducted by Anand Chetan, of 52\%. This difference may be due to the usage of intraoperative cholangiogram for identification of bile duct injuries.

Patients with significant bile leaks (Types A, C and D) presented within the first week after the procedure, type $\mathrm{E}$ (major injuries) are more likely to be identified intraoperatively whereas patients with slowly evolving stricture may present with jaundice often coupled with pain. Presenting symptoms and clinical manifestations of bile duct injuries were comparable to similar studies conducted worldwide.

Bile duct injuries are classified based on Stewartway classification, into 4 classes.

Class 1 - CBD mistaken for the cystic duct

Class 2 - lateral damage to the hepatic duct

Class 3 - CBD, CHD, right hepatic duct (RHD), left hepatic duct (LHD) transected and/or resected Class 4 - RHD mistaken for the cystic duct, RHD and right hepatic artery transected, lateral damage to the RHD from clips or cautery. Similar study was conducted by Bernhard W. Renz whose results are comparable to our study.

Table 3 Type of injury according to Stewart-way classification and comparison with similar studies

\begin{tabular}{|l|l|l|}
\hline Type of Injury & Present study & Bernhard W. Renz \\
\hline Class 1 & $8 \%$ & $6 \%$ \\
\hline Class 2 & $18 \%$ & $24 \%$ \\
\hline Class 3 & $68 \%$ & $60 \%$ \\
\hline Class 4 & & \\
\hline
\end{tabular}

Bismuth classification is useful for localization and prognosis after repair. Lillemoe $\mathrm{KD}$ and Anand Chetan have conducted similar studies and used this classification for localization of injuries. Type 1 - low hepatic duct stricture - hepatic duct stump $>2 \mathrm{~cm}$.

Type 2 - proximal common hepatic duct stricture - hepatic duct stump $<2 \mathrm{~cm}$
Type 3 - hilar stricture without any residual common hepatic duct - hepatic confluence intact Type 4 - destruction of hepatic duct confluence Type 5 - involvement of aberrant right sectorial hepatic duct alone or with concomitant stricture of the common hepatic duct 
Table 4 Bile duct injuries according to Bismuth classification and comparison with similar studies

\begin{tabular}{|c|c|c|c|}
\hline Type of Injury & Present study & Lillemoe KD & \\
\hline Type 1 & $56 \%$ & $21 \%$ & $60 \%$ \\
\hline Type 2 & $24 \%$ & $43 \%$ & $20 \%$ \\
\hline Type 3 & $12 \%$ & $21 \%$ & $12 \%$ \\
\hline Type 4 & $4 \%$ & $11 \%$ & $4 \%$ \\
\hline Type 5 & $4 \%$ & & \\
\hline & & & \\
\hline
\end{tabular}

The Strasberg classification has been developed to classify types of injury and is used extensively in describing bile duct injuries associated with laparoscopic cholecystectomy.

Class A - injury to small ducts in continuity with the biliary system, with cystic duct leak

Class B - injury to sectoral duct with consequent obstruction

Class C - injury to the lateral sectoral duct with consequent bile leak
Class D - lateral injury to extrahepatic ducts Class E1 - stricture $>2 \mathrm{~cm}$ distal to bifurcation Class E2 - stricture $<2 \mathrm{~cm}$ distal to bifurcation Class E3 - stricture at bifurcation

Class E4 - stricture involving right and left bile ducts

Class E5 - complete occlusion of all bile ducts

Table 5 Bile duct injuries according to Strasberg classification and comparison with other studies

\begin{tabular}{|c|c|c|c|}
\hline Type of Injury| & Present study & Anand chetan & Siklick JK \\
\hline Type A & $36 \%$ & $32 \%$ & $7.6 \%$ \\
\hline Type B & 0 & 0 & $7.6 \%$ \\
\hline Type C & 0 & 0 & $15.3 \%$ \\
\hline Type D & $12 \%$ & $16 \%$ & $2.3 \%$ \\
\hline Туре Е1 & $20 \%$ & $24 \%$ & $15.3 \%$ \\
\hline Tyре E2 & $20 \%$ & $16 \%$ & $15.3 \%$ \\
\hline Type E3 & $12 \%$ & $12 \%$ & $7.6 \%$ \\
\hline Type E4 & 0 & 0 & 0 \\
\hline Type E5 & 0 & 0 & $7.6 \%$ \\
\hline
\end{tabular}




\section{Conclusion}

Bile duct injuries are dreadful complications following open/laparoscopic cholecystectomy. The incidence is higher in females. Factors contributing to bile duct injuries are acute cholecystitis, cholangitis, pancreatitis and choledocholithiasis. Definitive repair should be done only after a detailed investigation to know the type and location of the injury.

Source of support from Department of General Surgery, Andhra medical college, Visakhapatnam

\section{References}

1. Roslyn JJ, et, al, 1993: Open cholecystectomy: a contemporary analysis of 42,474 patients. Ann Surg 218:129-137.

2. Strasberg SM, et, al, 1995: An analysis of the problem of biliary injury during laparoscopic cholecystectomy. J Am Coll Surg 180:101-125.

3. Adamsen S, et, al, 1997: Bile duct injury during laparoscopic cholecystectomy: a prospective nationwide series. . J Am Coll Surg 184:571-578.

4. Deziel DJ, et, al, 1993: Complications of laparoscopic cholecystectomy: a national survey of 4,292 hospitals and an analysis of 77,604 cases. J Am Coll Surg 165:9-14.

5. Mac Fadyen JB, et, al, 1998: Bile duct injury after laparoscopic cholecystectomy: the United States experience. Surg Endosc 12:315-321.

6. Richardson MC,et, al, 1996: Incidence and nature of bile duct injuries following laparoscopic cholecystectomy: an audit of 5913 cases. West of Scotland Laparoscopic Cholecystectomy Audit Group. Br J Surg 83:1356- 1360.

7. Wherry DC et, al, An external audit of laparoscopic cholecystectomy in the steady state performed in medical treatment facilities of the department of defence. Ann Surg ;1996.
8. The Southern Surgeons Club, 1991: A prospective analysis of 1,518 laparoscopic cholecystectomies performed by southern US surgeons.NEng J Med 324:1073-1078.

9. Gigot J,et, al 1997: The dramatic reality of biliary tract injury during laparoscopic cholecystectomy: an anonymous multicentre Belgian survey of 65 patients. SurgEndosc 11: 1171-1178.

10. Woods MS, et, al, 1994: Characteristics of biliary tract complications during laparoscopic cholecystectomy: a multiinstitutional study. Am J Surg 167:27- 34.

11. Russell JC, et, al 1996: Bile duct injuries,1989-1993. a state-wide experience. Connecticut laparoscopic cholecystectomy registry. Arch Surg 131:382-388.

12. Fletcher DR,et, al 1999: Complications of cholecystectomy:risks of the laparoscopic approach and protective efforts of operative cholangiography. Ann Surg 229:449-457.

13. Walsh RM, et, al 1998:Trends in bile duct injuries from laparoscopic cholecystectomy. J Gastrointest Surg 2:458-462.

14. Carroll BJ, et, al 1996: Routine cholangiography reduces sequelae of common bile duct injuries. Surg endoscopic 10:1194-1197.

15. Braasch JW. Congenital anomalies of the gallbladder and bile ducts. Surg Clin North Am 1958:38-627.

16. Johnston EV, Anson BJ. Variations in the formation and vascular relationships of the bile ducts. Surg Gynecol Obstet 1952.

17. Newman HF, Northrup JD. Extrahepatic biliary tract anatomy. West J Surg Obstet Gynecol 1963:71-59.

18. Davidoff AM, et, al, 1992: Mechanisms of major biliary injury during laparoscopic cholecystectomy: Ann Surg 215:196-208.

19. Healey JE Jr, Schroy PC Anatomy of the biliary ducts within the human liver: 
analysis of the prevailing pattern of branchings and the major variations of the biliary ducts. Arch Surg1953;66:599.

20. Hermann RE. Manual of Surgery of the Gallbladder, Bile Duct and Endocrine Pancreas. New York: Springer-Verlag, 1979.

21. Michels NA. Blood Supply and Anatomy of the Upper Abdominal Organs. Philadelphia: Lippincott, 1955.

22. Daseler E, Anson B, Hambley W, Reiman A. Cystic artery and constituents of the hepatic pedicle. Surg Gynecol Obstet 1947;85: 47.

23. Van Damme JP, Bonte J. The branches of the celiac trunk. Acta Anat1985;122:110.

24. Van Damme JP. Behavioral anatomy of the abdominal arteries. Surg Clin North Am 73(4):699-725, 1993.

25. Suzuki T, Nakayasu A, Kauabe K, Takeda $\mathrm{H}$, Honjo I. Surgical significance of anatomic variations of the hepatic artery. Am J Surg 1971;122:505.

26. Healey JE Jr, Schroy PC, Sorensen RJ. The intrahepatic distribution of the hepatic artery in man. J Int Coll Surg1953;20:133.

27. Nikolić V. Arterecystiquere currente. Bull Assoc Anat 1967;136: 739.

28. Balija M, Huis M, Nikolić V, Štulhofer M. Laparoscopic visualization of the cystic artery anatomy. World J Surg1999;23:703707

29. Northover JMA, Terblanche J, 1979: A new look at the arterial blood supply of the bile duct in man and its surgical implications.Br J Surg 66:379-384.

30. Parke WW, Michels NA, Ghosh GM. Blood supply of the common bile duct. Surg Gynecol Obstet 1963:117:47. 